\title{
Mortalidade de leitões em aleitamento associada à injeção com penicilina em uma agroindústria no sul do Brasil
}

\author{
Mortality of suckling piglets associated with penicillin \\ injection in commercial production in Southern Brazil \\ Patrícia Schwarz ${ }^{1}$, Marisa Ribeiro de Itapema Cardoso ${ }^{1}$, J uliana Calveyra ${ }^{1}$, \\ Alessandra Blacene Sella ${ }^{1}$, David Driemeier ${ }^{2} \&$ David Emilio Santos Neves de Barcellos ${ }^{3}$
}

\begin{abstract}
RESUMO
O uso de antimicrobianos, como as penicilinas, é comum na maternidade, como profilático em leitões recém nascidos ou para o tratamento de diversas infecções bacterianas. As penicilinas em suas diferentes formulações (como a penicilin-procaína e amoxicilina) são bastante usadas, por seu espectro compatível com algumas das principais infecções prevalentes em leitões na maternidade. Raramente são registrados casos de intoxicações, cursando com mortalidade de leitões, ou reações anafiláticas. Este trabalho descreve um surto de mortalidade na fase de aleitamento, após administração de produto antimicrobiano à base de penicilina e estreptomicina. Os leitões tratados (157) pertenciam a duas granjas produtoras de leitões, integradas de uma agroindústria no sul do Brasil. Os sintomas presentes foram inquietação, dispnéia, tremores musculares, vômito e diarréia, todos ocorrendo num período máximo de 15 minutos a duas horas após administração do antimicrobiano. A mortalidade (13\%) foi considerada decorrente de uma reação de anafilaxia posterior à administração de antimicrobianos à base de penicilina.
\end{abstract}

Descritores: Anafilaxia, penicilina, maternidade, suínos.

\section{ABSTRACT}

Antimicrobials, such as penicillin, are frequently used in pork production in the prophylaxis and treatment of bacterial diseases in weanling piglets and suckling piglets and sows, therefore the penicillins are usually regarded as one of safest groups of antimicrobials for use in animals. Uncommonly, cases of intoxication with mortality and anaphylaxis have been reported. In the present report we describe an outbreak of mortality in 157 pre-weaning piglets, after injection of penicillin with streptomycin. Two comercials breeder herds, from two different farms, but with similar environment, management and genetic characteristics presented mortality episodes in Southern Brazil. The main symptoms were uneasiness, dyspnea, shivering, emesis and diarrhea in piglets treated commencing 15 minutes after injection and continuing for up to two hours. The cause of mortality (13\%) in the piglets was an anaphylactic reaction, caused by penicillin injection.

Key words: Anaphylaxis, penicillin, weanling piglets, pigs. 


\section{INTRODUÇÃO}

A produtividade na suinocultura depende de vários fatores, entre os quais a mortalidade nas diferentes fases da produção apresenta um impacto muito significativo. Especialmente na maternidade, as mortes de leitões por causas infecciosas como diarréias, artrites ou meningites bacterianas são muito prevalentes. Entre as etiologias não infecciosas, destaca-se o nascimento de leitões inviáveis em função de hipóxia durante o parto, esmagamento e a sufocação [14]. Outras causas não infecciosas de mortalidade, como intoxicações, podem gerar surtos esporádicos de mortalidade em leitões na fase de aleitamento.

O uso de antibióticos é comum na maternidade, como profilático em leitões recém nascidos ou em outras faixas etárias para o tratamento de diversas infecções bacterianas. As penicilinas em suas diferentes formulações (como a penicilin-procaína e amoxicilina) são bastante usadas, por seu espectro compatível com algumas das principais infecções prevalentes em leitões na maternidade. Casos de intoxicações cursando com mortalidade de leitões ou de reações suspeitas de anafilaxia após a administração dessa droga foram descritas anteriormente $[1,4,6,9,10,12,13]$. Existe uma outra forma de reação adversa bem reconhecida, a de abortos em fêmeas no final da fase de gestação $[8,11]$.

O presente trabalho descreve um surto de mortalidade de leitões na fase de aleitamento, após administração de produto antibiótico à base de penicilina e estreptomicina.

\section{MATERIAIS E MÉTODOS}

O problema ocorreu numa granja de produção de leitões, alojando aproximadamente 1200 matrizes, situada no estado do Rio Grande do Sul. O relato inicial foi de mortalidade de leitões com 7 a 15 dias de idade, ocorrendo 1 a 3 horas após a administração de um produto antimicrobiano à base de penicilina.

Os sinais clínicos prévios à mortalidade foram genericamente referidos pelo gerente da granja como "sintomatologia nervosa". Na fase anterior à visita, haviam adoecido 30 leitões de um total de 50 medicados, com a mortalidade de 23 animais.

Foi realizada uma visita para análise dos sintomas e para coleta de materiais com a finalidade de realização de exames laboratoriais. Numa visita posterior, foi realizado o uso controlado do medicamento, para observação da ocorrência dos sintomas suspei- tos, sendo selecionadas leitegadas de 16 matrizes, onde 8 porcas foram medicadas anteriormente com penicilina e 8 não foram medicadas. A dose utilizada em todos os casos foi de $0,5 \mathrm{~mL}$ do produto antimicrobiano contendo penicilina e estreptomicina.

\section{RESULTADOS}

No dia da primeira visita havia apenas uma leitegada com leitões apresentando o problema denunciado. Dentro da leitegada, havia um leitão com sintomas. A causa dessa e das outras medicações que resultaram na mortalidade eram ocorrências sanitárias rotineiras, como diarréia, artrites, apatia e atraso de desenvolvimento. O exame clínico do leitão afetado mostrou salivação excessiva, taquipnéia, taquicardia e respiração ofegante. O quadro havia aparecido aproximadamente 2 horas após a aplicação de produto à base de penicilina-estreptomicina. O exame clínico não confirmou a suspeita do encarregado pelo plantel, que havia diagnosticado sintomatologia nervosa.

Foi realizada a necropsia do leitão afetado, sendo que as principais alterações observadas foram fígado de coloração alterada e rim com aspecto pálido. Não foram encontradas anormalidades no exame do cérebro.

Foram coletados materiais dessas e de outras vísceras para a realização de exames bacteriológicos e histopatológicos. Não houve crescimento de microorganismos patogênicos a partir dos cultivos das vísceras.

O exame histopatológico, demonstrou lesão degenerativa do sistema nervoso central, indicando possível anóxia. Áreas de malácia no córtex cerebral e desorganização com presença de neurônios retraídos, com citoplasma eosinofílico, ainda foram identificadas.

Numa segunda visita, o produto suspeito foi injetado em 157 leitões com 7 dias de vida, oriundos de 16 matrizes. Ocorreu sintomatologia compatível com choque anafilático 1 a 3 horas após a aplicação em 53 leitões (34\%). Os animais mostraram sinais de inquietação, salivação e respiração ofegante, com dispnéia e diarréia. Na maioria dos afetados houve remissão progressiva dos sintomas para a cura, mas em 20 leitões (13\%) ocorreu evolução para a morte, aparentemente por insuficiência respiratória. Na necropsia, as lesões foram similares às observadas na primeira visita.

\section{DISCUSSÃO}

Os maiores efeitos adversos registrados com o uso de penicilinas têm sido anafilaxia aguda e co- 
lapso, mas reações de hipersensibilidade mais leves (cursando apenas com febre, urticária e edema angioneurítico) foram relatadas anteriormente $[2,3,7,9,13]$. A penicilina em contato com o sistema nervoso central pode causar estimulação, tremores musculares e convulsões. Esses efeitos foram obtidos pela injeção experimental direta no córtex cerebral de animais [6].

A intoxicação de suínos a campo foi relatada anteriormente por diferentes autores [2,5,7,9]. Os sinais clínicos, evolução e lesões encontradas nos animais afetados foram similares às verificadas no nosso relato. Um dos autores [2] sugeriu que os sinais clínicos haviam sido desencadeados por uma reação de anafilaxia. No nosso caso, a tentativa de tratar alguns leitões doentes com anti-histamínicos apresentou resultado apenas regular, ocorrendo ainda mortes após a aplicação desse tipo de produto. Outro autor [3] sugeriu que a reação fosse devida a um quadro tóxico, causado por um produto alterado devido a um tempo de conservação longo em temperatura inadequada. Essa hipótese não pode ser afastada no presente caso, pois os relatos sobre as condições de conservação do antibiótico antes do uso foram contraditórios.

Uma forma típica de hipersensibilidade aguda em cães com tremores, salivação, vômito e congestão cutânea foi registrada por Clarke [5] dentro de 15 minutos após a injeção intramuscular de penicilina procaína. Nesse caso, o autor suspeitou de que o leite da mãe pudesse ter sido a origem da sensibilização à penicilina.

Na presente descrição, a sintomatologia foi similar à descrita por esse autor (Figuras 1,2, 3 e 4). Como existem produtos que têm em sua composição penici-

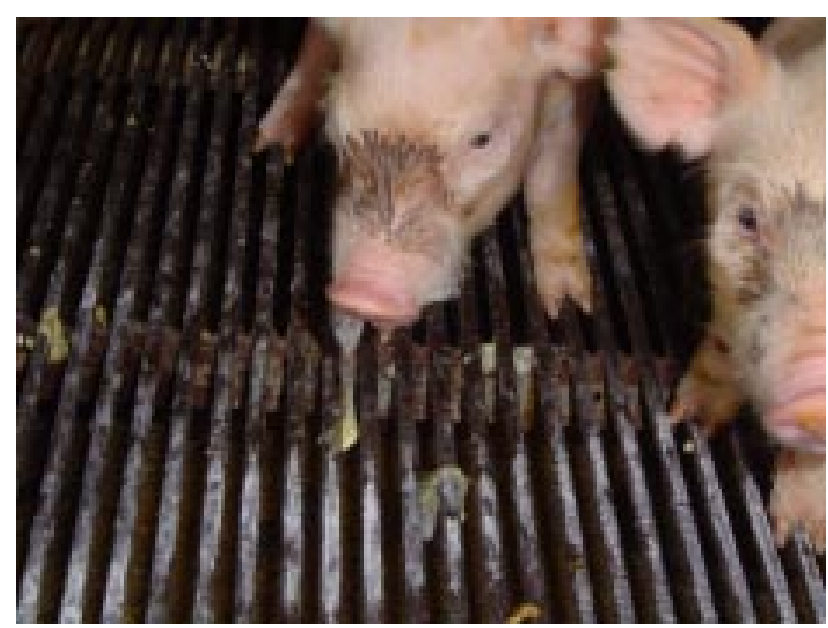

Figura 1. Salivação excessiva de leitão com duas semanas de vida, após administração de penicilina [Foto: Patrícia Schwarz].

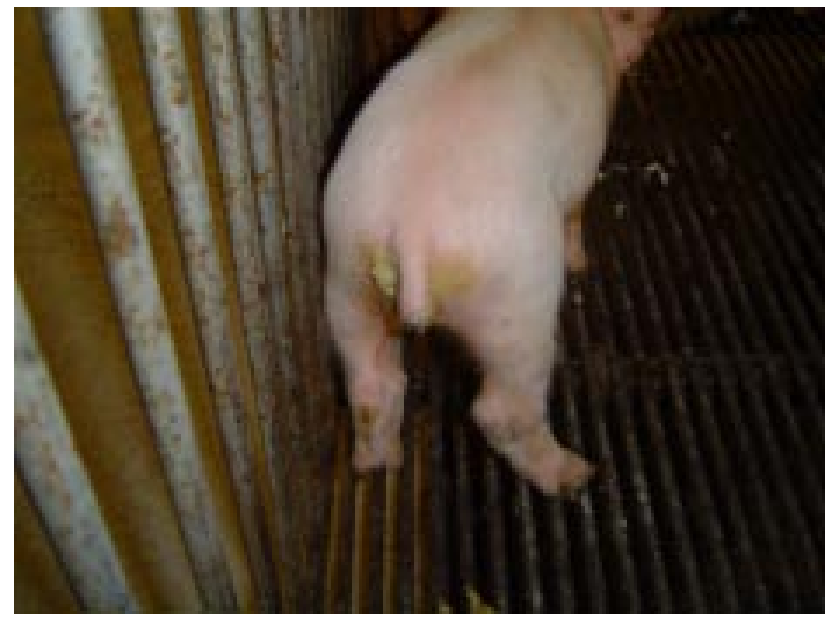

Figura 2. Apresentação de diarréia de leitão com duas semanas de vida, após administração de penicilina [Foto: Patrícia Schwarz].

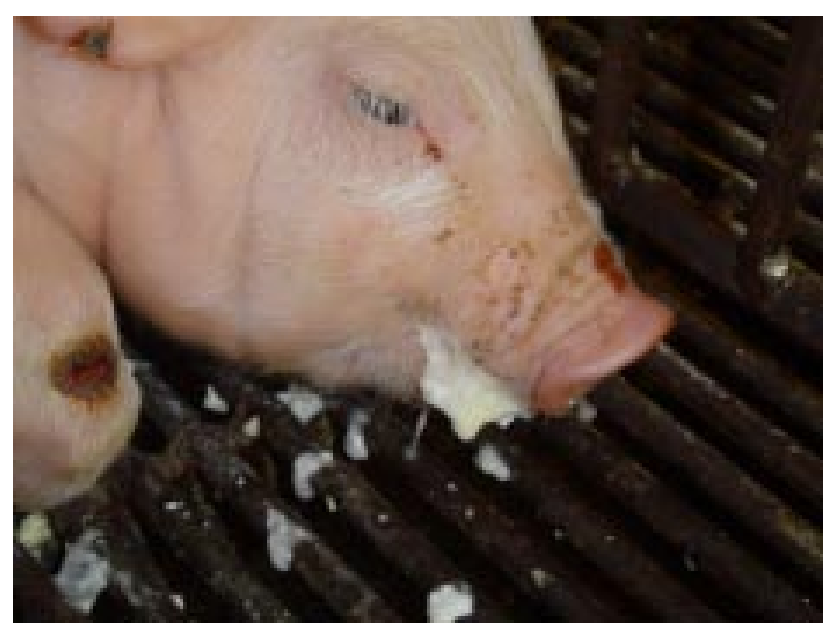

Figura 3. Vômito e Prostração de leitão com duas semanas de vida, após administração de penicilina [Foto: Patrícia Schwarz].

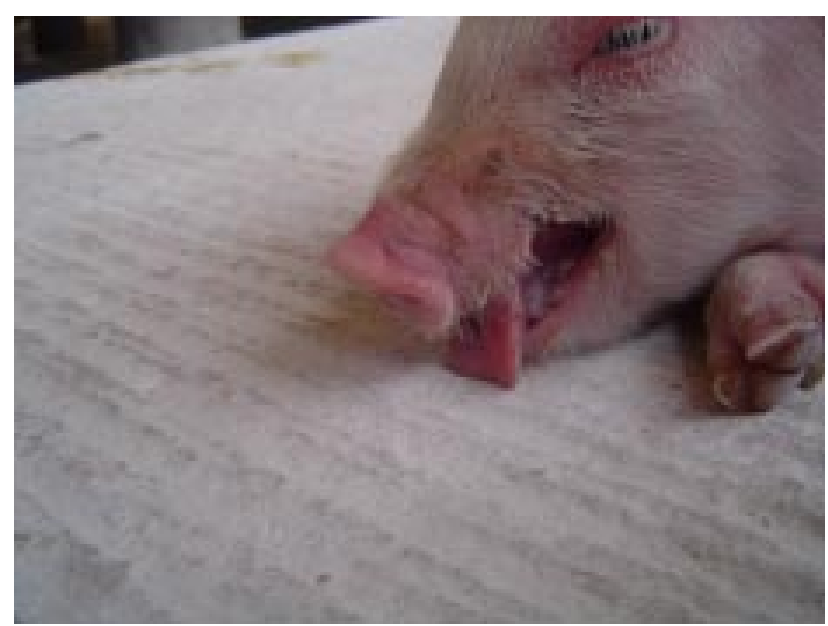

Figura 4. Dispnéia após apresentação de sinais de salivação, diarréia e vômito de leitão com duas semanas de vida, após administração de penicilina [Foto: Patrícia Schwarz]. 
linas e que são administrados rotineiramente a porcas prenhas (como vacinas que têm em seu diluente algumas penicilinas), existe teoricamente a possibilidade de que situação similar pudesse ter desencadeado o atual problema. Nessa granja, eventuais problemas clínicos em porcas gestantes eram tratados rotineiramente com antibióticos, entre os quais penicilinas, o que poderia gerar a sensibilização via colostro de leitegadas nascidas das fêmeas medicadas. No entanto, como descrito anteriormente, a escolha de leitegadas para a administração controlada do produto, foi determinada pela amostragem de matrizes medicadas e não medicadas anteriormente com penicilina, não havendo diferenças na avaliação de morbidade e mortalidade de leitões, quando relacionada à medicação das matrizes. Porém, para afirmarmos a inexistência de interferência dos anticorpos maternos na sensibilização dos leitões seria necessário ampliar este estudo e avaliar fatores inerentes ao momento de medicação das porcas, doses administradas, mas, principalmente, a amplitude de transferências de leitões até a data avaliada (sétimo dia de aleitamento).

\section{CONCLUSÕES}

A injeção de penicilina em leitões na fase de aleitamento foi capaz de causar reações adversas, cursando com dispnéia, salivação excessiva, diarréia e mortalidade elevada entre animais afetados.

\section{REFERÊNCIAS}

1 Avellini G. 1955. Generalità sull'impiego della Penicillina e Estreptomicina. Veterinaria Farmitalia. 4: 3-13.

2 Desrosiers R., Sauvageau R.\& Beauregard M. 1988. Carbadox and procaine peniciliin toxicity in pigs. In: Proceedings of the 10th International Pig Veterinary Society Congress (Rio de Janeiro, Brasil). p.249.

3 Embrechts E. 1982. Procaine penicillin toxicity in pigs. Veterinary Record. 111: 314-315.

4 Henry S.C. \& Upson D.W. 1992. Therapeutics In: Leman A., Straw E.B., Mengeling W.L., D’ Allaire S. \& Taylor D.J. (Eds). Diseases of swine. 7th edn. Ames: Iowa State University Press, pp.837-846.

5 Clarke P.B. 1960. Penicillin intoxication. Veterinary Record. 72: 1054.

6 Jones M., Toral M.T. \& Chavarria M. 1959. Farmacologia y Terapeutica Veterinarias. Mexico City: Uteha Ed., pp.406-425.

7 Lambert H.P. \& O'Grady F.W. 1992. Penicillins. In: Antibiotic and chemotherapy. 6th edn. Edinburgh: Churchill Livingstone Ed., pp.191-230.

8 Lynch P.J. 1984. Abortion in sows after injection of a suspension of penicillin and streptomycin. Australian Veterinary Journal. 61: 29.

9 Marshall A.B. 1980. Penicillin: suspected adverse reaction. Veterinary Record. 106: 207-208.

10 Mckinnon J.D. 1992. Drugs use and abuse: Iatrogenics or farmacogenics. Pig Veterinary Journal. 29: 149-160.

11 Nurmio P. 1980. Penicillin G procaine: a possible cause of of embryonic death in swine. Veterinary Record. 106: 97-98.

12 Powers T.E. \& Garg R.C. 1980. Pharmacotherapeutics of newer penicillins and cephalosporins. Journal of the American Veterinary Medical Association. 176: 1054-1059.

13 Prescott J.F., Baggot J.D. \& Walker R.D. 2000. Beta-lactam antibiotics. In: Antimicrobial Therapy in Veterinary Medicine . 3rd edn. Ames: Iowa State University Press, pp.105-133.

14 Sobestiansky J., Barcellos D.E.S.N., Mores N., Oliveira S.J. \& Carvalho L.F. 1993. Patologia e Clínica Suína. Lajeado: Cometa Ed., 350 p.

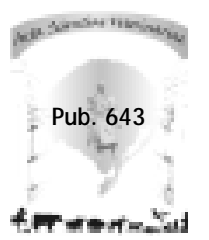

